\title{
High-density \\ Planting in a \\ Precision \\ Cultural System \\ for Vegetable \\ Production
}

\author{
Regina P. Bracy, \\ R.L. Parish', and \\ W.A. Mulkey ${ }^{3}$
}

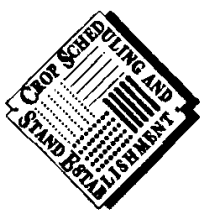

Additional index words. Brassica oleracea, Brassica juncea, Spinacia oleracea, precision seeding, mechanical cultivation, plant density, narrow-row spacing, multiple plant rows

Summary. A cultural system consisting of precision seeding on shaped beds,

followed by cultivation using mechanically guided equipment, was developed and evaluated with several vegetable crops. The precision cultural system allowed for growing the crops at high plant populations by using precision planting and exact cultivation of multiple narrow rows of plants on wide beds. Eight field experiments were conducted from 1987 to 1989 on broccoli (Brassica oleracea var. botrytis L.), cabbage (BraEa oleracea var. capitata L.) mustard (Brassica juncea var. crispfolia L.), and spinach (Spinacia oleracea L.) to evaluate production of these crops on single- and multiple-row configurations on narrow $(1-\mathrm{m})$ and wide $(2-\mathrm{m})$ beds. The precision cultural system was assessed to be an excellent method for production of the small-seeded crops that were tested. Yield was highest for cabbage, mustard, and spinach planted in six rows on 2-m beds compared with four-, two-, or one-row beds. Multiple-row configurations did offer yield advantages over the single-row configuration for broccoli production.

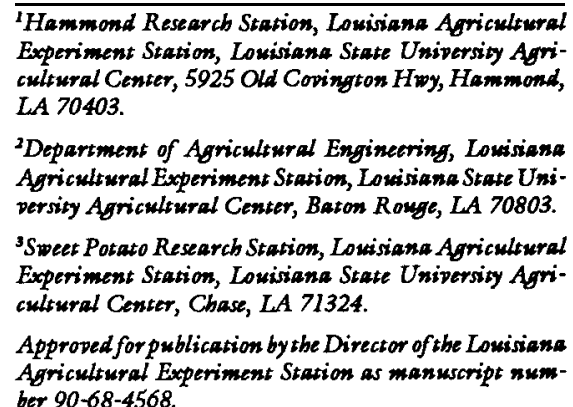


C ommercial vegetable production has been identified as an alternative enterprise for producers of traditional agronomic row crops in many areas of the country (Arthur, 1988; Denison and Paxton, 1987; Klassen, 1988). Successful production of vegetables, however, requires a more intensive cultural management system than is currently used for growing most agronomic crops. A research program was initiated by the Louisiana Agricultural Experiment Station to develop cultural and mechanical systems needed for commercial vegetable production.

The concept of multiple narrow rows on wide beds has been evaluated and demonstrated successfully with several agronomic crops, including cotton (Gossypium hirsutum L.) (Parish et al., 1973),soybeans (Glycine max Merrill), grain sorghum (Sorghum vulgare var. subglabrescens A.F. Hill), and corn (Zea mays L.) (Parish and Mermoud, 1974). These studies showed an advantage in yield from the use of multiple rows and demonstrated how shaped beds could be cultivated precisely using equipment directed by coneguide wheels. Plant density is an important variable in obtaining maximum yield and uniform maturity ofvegetable crops. Studies with broccoli, cauliflower (Dufault and Waters, 1985), and cabbage (Mulkey and Porter, 1987) have indicated that increasing plant density by decreasing in-row spacing can result in higher yields. Optimum plant densities are likely to be achieved by varying both in-row and between-row spacings. However, little work has been done on narrow-row configurations for vegetable crops.

A primary constraint to narrowrow configuration is likely to be weed control. Vegetable seedlings, especially from small-seeded crops, do not compete well with weeds. Because herbi-

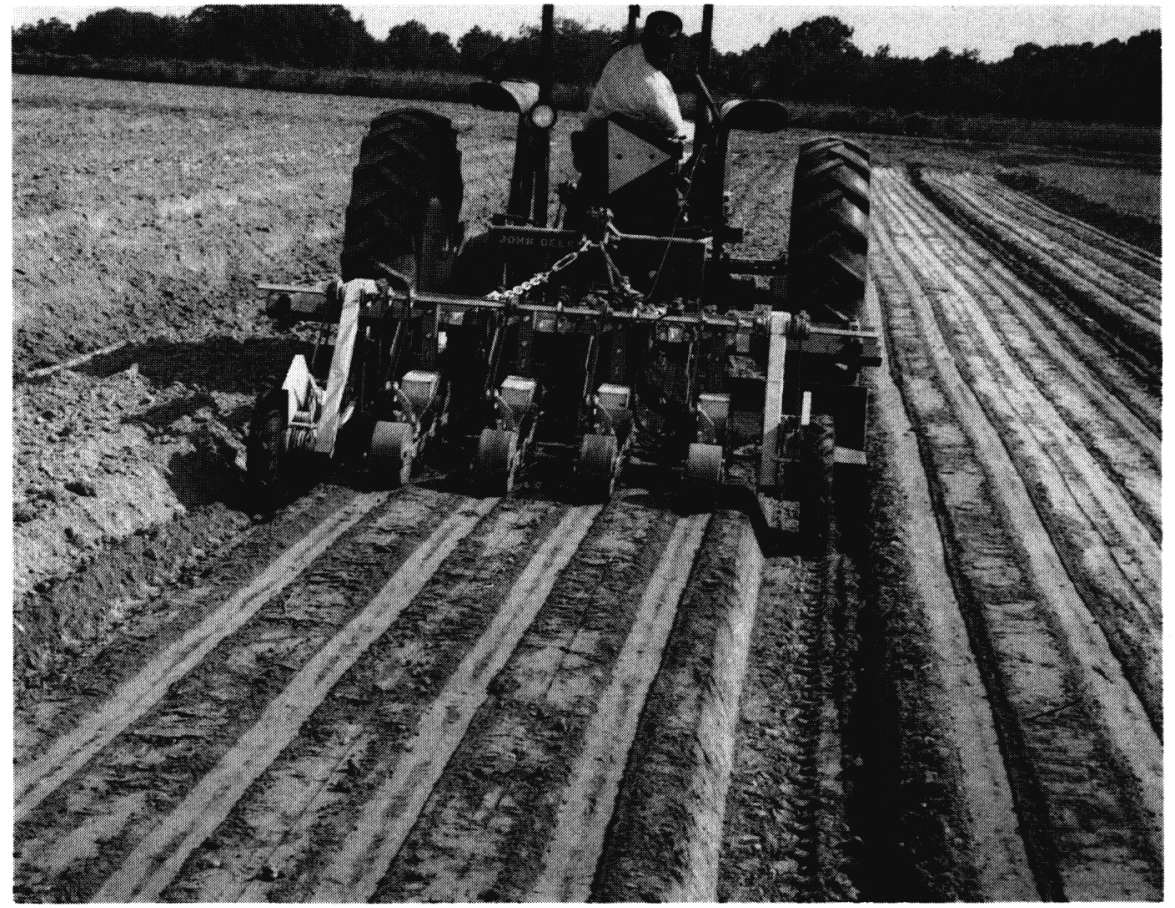

Fig. 1. Precision seeding of four rows on a 2-m bed with Stanbay seeders mounted directly on the rear of the bed sbaper.

cides labeled for use in many vegetables are limited, mechanical weed control often is essential for successful production. However, cultivation of multiple narrow rows is difficult, if not impossible, with conventional equipment (Parish et al., 1988). These factors suggest a need for more research on a precision cultural system for growing vegetables.

This study was designed to develop and evaluate a multiple-row, wide-bed system for vegetable production. The effects of plant density on yield and quality of broccoli, cabbage, mustard, and spinach were investigated by varying row number and bed size.

Precision cultural system. Because plant residue would reduce the effect of a precision-shaped bed, the precision cultural system developed for these

Table 1. Soil type and cultural practices used for plant density experiments in two Louisiana locations.

\begin{tabular}{lcccc}
\hline Crop & Cultivar & Planting date & Location & No. harvests \\
\hline Broccoli & Baccus & 25 Aug. 1987 & Bastrop & 4 \\
Cabbage & Solid Blue 770 & 25 Aug. 1987 & Bastrop & 4 \\
& Asgrow 5117 & 29 Aug. 1988 & Hammond & 2 \\
& Asgrow 5116 & 1 Mar. 1989 & Hammond & 3 \\
Mustard & Fla. Broadleaf & 21 Sept. 1988 & Hammond & 1 \\
& Fla. Broadleaf & 1 Nov. 1988 & Hammond & 1 \\
& Fla. Broadleaf & 27 Jan. 1989 & Hammond & 1 \\
Spinach & Shamrock & 7 Dec. 1988 & Hammond & 1
\end{tabular}

Soil type at Bastrop was Sterlington silt Loam; soil type at Hammond was Cababa fine sandy loam. studies began with a clean area. After beds were formed using a disk bedder, a sled-type bed-shaper was used to flatten and firm the top and sides of the bed, assuring that the bed was of a precise height and width with a smooth, flat top (Chaney and Parish, 1987). The beds were shaped to a height of 15 $\mathrm{cm}$ and were either $1 \mathrm{~m}$ on center with a $51-\mathrm{cm}$ flat top or $2 \mathrm{~m}$ on center with a $152-\mathrm{cm}$ flat top. Ground-driven Stanhay S870 seeders were mounted directly on the rear of the bed-shaper (Fig. 1). Proper positioning of the planters on the bed-shaper assured that the planted rows were centered on the top of the beds.

All subsequent operations (fertilizer application and cultivation) were guided by coneguide wheels that followed the shaped bed and held the different implements in correct position relative to the plant rows. The coneguide wheels locked onto the sides of the shaped bed, which relieved the tractor driver of the need to steer precisely.

Plant culture. Nine field experiments using five vegetable crops were conducted at Bastrop, La., in 1987 and Hammond, La., in 1988 and 1989. Experiments with broccoli (1987) and spinach (1988) were conducted once at one location. Experiments were conducted with cabbage (two loca- 


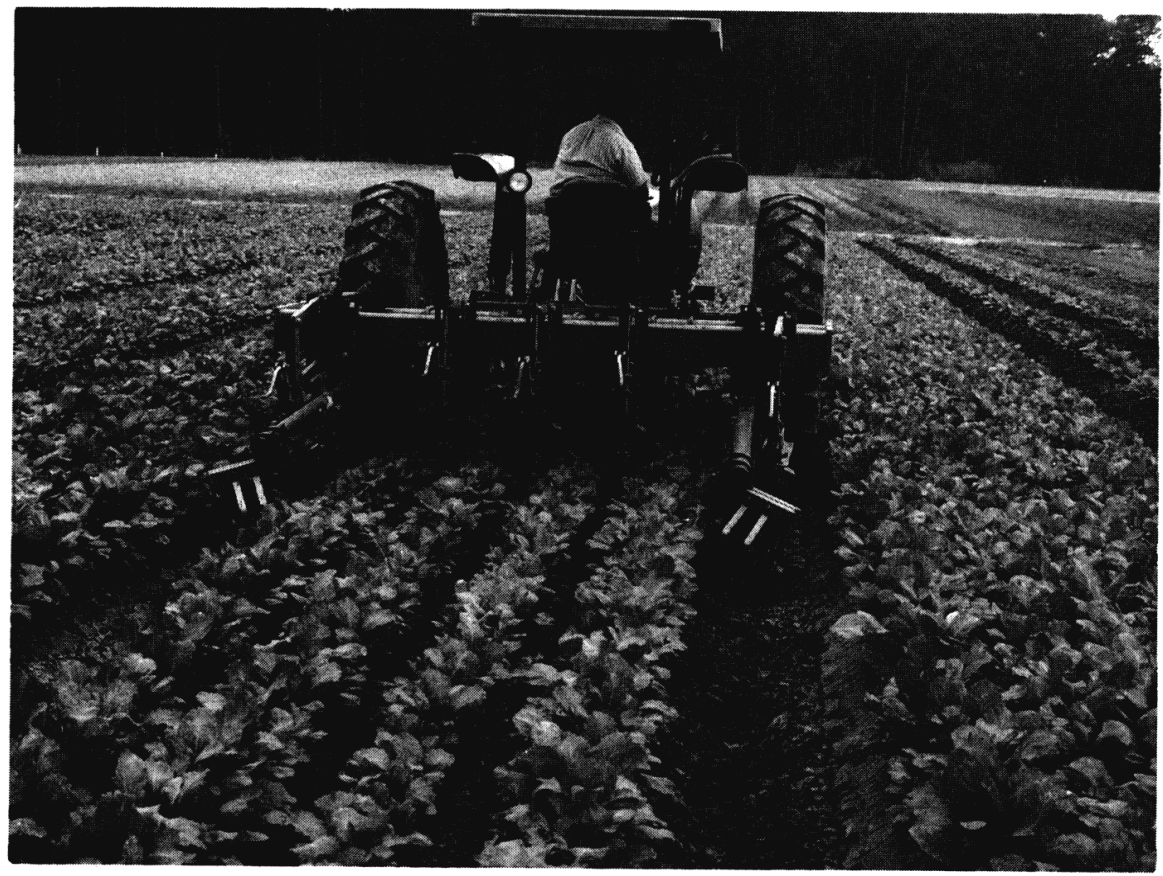

Fig. 2. Sweop cultipution of four rows of TFla Broadleaf mestard spaced 38 cme aport on a 2-m bed witb come-greide wheels used for greidonsce on bed tions) and mustard (one location) in three plantings of each crop. A randomized complete blockdesign of row configurations (replicated four times) was used for each study. Crops, cultivars, and row configurations varied with years and locations. Soil types, crops, cultivars, and other cultural practices applicable to each location are presented in Table 1.

Row configurations included one row on $1-\mathrm{m}$ beds, two rows $26 \mathrm{~cm}$ apart on $1-\mathrm{m}$ beds, four rows $38 \mathrm{~cm}$ apart on 2-m beds, and six rows $26 \mathrm{~cm}$ apart on 2-m beds. The planters were equipped with two- or three-line openers that, when used in combination with the appropriate seed belts, enabled multiple lines of seed to be drilled from a single row unit. One plant line/row was used in planting the single-row plots of mustard and spinach. The openers were used for planting two and three lines/row of mustard and spinach, respectively, in all other configurations. Broccoli and cabbage were seeded in one plant line/ row for all row configurations. Seed spacings within row (WIR) were $9 \mathrm{~cm}$ for broccoli and cabbage and $4 \mathrm{~cm}$ for mustard and spinach. The cabbage was thinned manually with a hoe to a 30-cm WIR spacing when plants were $9 \mathrm{~cm}$ high. Seeding rates for each crop by row configuration are listed in Table 2.
Fertilizer was applied $8 \mathrm{~cm}$ deep and $13 \mathrm{~cm}$ beside the crop row in a single band for the one-row configuration, in two bands for the two- and four-row configurations, and in three bands for the six-row configuration. Accurate placement of the fertilizer with respect to crop row was ensured by using cone-guide wheels on the fertilizer applicator to hold the machine on the beds at the proper location. Fertilization, based on Louisiana Cooperative Extension Service recommendations (Cannon and Boudreaux, 1987), was adjusted according to soil analysis and varied proportionately with row configuration. Preplant fertilizer for the broccoli and cabbage was applied at the rate of 22N-29P-63K kg ha-1 (20N-26P$56 \mathrm{~K} \mathrm{lb} /$ acre) for single-row plots, 45N-58P-112K kg ha-1 $\mathrm{K}^{-10 \mathrm{~N}-52 \mathrm{P}-}$ $100 \mathrm{~K} \mathrm{lb} /$ acre) for two- and four-row plots, and $67 \mathrm{~N}-90 \mathrm{P}-168 \mathrm{~K} \mathrm{~kg} \mathrm{ha}^{-1}$
(60N-80P-150Klb/acre) for six-row plots. For mustard and spinach, preplant fertilizer was applied at the rate of $36 \mathrm{~N}-47 \mathrm{P}-90 \mathrm{Kkg} \mathrm{ha}^{-1}$ (32N-42P$80 \mathrm{~K} \mathrm{lb} /$ acre) for single-row plots, $54 \mathrm{~N}-71 \mathrm{P}-133 \mathrm{~K} \mathrm{~kg} \mathrm{ha}{ }^{-1}$ (48N-63F $119 \mathrm{~K} \mathrm{lb} /$ acre) for two- and four-row plots, and $72 \mathrm{~N}-94 \mathrm{P}-188 \mathrm{~K} \mathrm{~kg} \mathrm{ha}^{-1}$ (64N-84P-168Klb/acre) for six-row plots. Nitrogen, in the form of ammonium nitrate, was applied to the crops in one, two, or three sidedressings, beginning when plants were $10 \mathrm{~cm}$ tall and continuing at 2-week intervals. Broccoli and cabbage at the Bastrop location and cabbage at the Hammond location were sidedressed with a total of 78 (70), 145 (129), and $225 \mathrm{~kg} \mathrm{ha}^{-1}$ (201 lb/acre) of $\mathrm{N}$ for single-, two- and four-, and six-row plots, respectively. Mustard was sidedressed with 40 (single-, two-, and four-row configurations) and 50 (sixrow configuration) $\mathrm{kg} \mathrm{ha}^{-1}$ (36 and 45 $\mathrm{lb} /$ acre) of N. Spinach was sidedressed with 56 (single-, two-, and four-row configurations) and 78 (six-row configuration) $\mathrm{kg} \mathrm{ha}^{-1}$ (50 and $70 \mathrm{lb} / \mathrm{acre}$ ) of $\mathrm{N}$.

Weed control was accomplished by herbicide application and ensuing mechanical cultivations. In the broccoli, cabbage, and mustard experiments, trifluralin [2,6-dinitro $N, N$ dipropyl-4-(trifluoromethyl)benzamine] was applied preplant, incorporated at the rate of $1.7 \mathrm{~kg} \mathrm{ha}^{-1}$. In the spinach experiment, diethatyl ethyl [ $N$ (chloroacetyl)-N-(2,6diethylphenyl) glycine ethyl ester] was applied immediately after planting at the rate of 6.8 $\mathrm{kg} \mathrm{ha} \mathrm{a}^{-1}$. Each experiment was cultivated once or twice 3 to 7 weeks after planting using sweep cultivators directed by cone-guide wheels (Fig. 2). Although rolling cultivator gangs were used to control weeds on the sides of the row, bed shape was maintained throughout the cultivation procedure. The cultivators were set to leave an uncultivated band of $15 \mathrm{~cm}$ on each
Table 2. Seeding rutes for broccoli, cabbage, mestard, and spinacb in parious row confignurer tions.

\begin{tabular}{lcccc}
\hline Row & \multicolumn{4}{c}{ Seeds planted/ha } \\
\cline { 2 - 5 } configuration & Broccoli & Cabbage & Mustard & Spinach \\
\hline One row/1-m bed & 113,900 & $113,900(34,170)^{\mathrm{z}}$ & 242,400 & 242,430 \\
Two rows/1-m bed & 227,900 & $227,900(64,582)$ & 972,100 & $1,454,700$ \\
Four rows $/ 2$-m bed &.$--y$ & $227,900(64,582)$ & 972,100 & $1,454,700$ \\
Six rows $/ 2$-m bed & 342,000 & $342,000(96,873)$ & $1,454,900$ & $2,182,400$ \\
\hline
\end{tabular}

${ }^{8}$ Numbers in parentheses indicate population after thinning to 30-cm WIR spacing.

'Not planted in this configuration. 
row. Cultivation timing was determined by the amount and size of weeds present.

Standard commercial production, cultural, and pesticide practices were followed throughout the season (Cannon and Boudreaux, 1987). Overhead sprinkler irrigation was used to supplement natural rainfall to maintain a 4-cm minimum supply of moisture per week.

Broccoli and cabbage were harvested manually when head size and density indicated maturity, and then trimmed according to market specifications (Cannon and Boudreaux, 1987). Marketable head weights and numbers were measured from 6-m plots during each harvest. Mustard was harvested when the leaves were 38 to $46 \mathrm{~cm}$ tall. Spinach was harvested when eight to 10 mature leaves were present and plants were $15 \mathrm{~cm}$ tall. Bulk weight of leaves harvested from 3-m plots was used to determine yield of mustard and spinach. Number of harvests for each crop at each location are listed in Table 1.

Analyses ofvariance were performed on yield and head size data and revealed no significant location $\times$ rowconfiguration effect; therefore, only main effect means of row configuration are presented. Means were separated by Duncan s multiple range test (5\% level).

A problem with the bedding method was experienced at the Bastrop location. A 2-m disk bedder with markers was not available to lay out the rows, so a $1-\mathrm{m}$ disk bedder was used to make the beds, which then were dragged down almost flat with a harrow and rebedded to $2 \mathrm{~m}$. This resulted in loose, drier soil in the center of the 2-m beds. Subsequent experience has shown that this is not a prob- lem if the wide beds originally are laid out with a $2-\mathrm{m}$ bedder. Germination and stand of broccoli and cabbage were not affected by this difficulty. Cauliflower that was planted at the Bastrop location at the same time appeared more sensitive to the drying conditions, resulting in delayed germination and a reduction in the final stand in the center two rows. Consequently, the data from the cauliflower experiment were not included in this report.

Yield from broccoli grown in twoand six-row plots was 36\% higher than yield from broccoli grown in singlerow configuration during one season of testing (Table 3). Marketable heads for fresh-market broccoli (packed three or four heads/bunch, 18 bunches/ 9.5-kg box) should weigh 130 to 200 g. Head size was adequate for broccoli grown at all row configurations, but was largest for broccoli in single-row plots.

Yields were higher by $17 \%, 23 \%$, and $16 \%$ with cabbage planted in the six-row configuration as compared with cabbage planted in single-, two-, and four-row configurations, respectively. Yields were not different among $\mathrm{cab}$ bage grown in the one-, two-, or fourrow plots, although average head weight was much higher for cabbage planted in single rows. Head size, based on fresh-market requirements of 18 to 22 heads in a 50-lb sack, was adequate for cabbage grown in all row configurations. Seeding rates for the two-row and four-row configurations were identical, but distance between rows was greater in the four-row $(38-\mathrm{cm})$ than in the two-row $(26-\mathrm{cm})$ configuration, which may account for the larger head weights in cabbage planted in four rows/bed.

Mustard grown in six rows on 2-

Table 3. Effects of row configurations on marketable yields of broccoli, cabbage, mustard, and spinacb.

\begin{tabular}{|c|c|c|c|c|c|c|}
\hline \multirow[b]{2}{*}{$\begin{array}{l}\text { Row } \\
\text { configuration }\end{array}$} & \multicolumn{2}{|c|}{ Broccoli: } & \multicolumn{2}{|c|}{ Cabbage" } & \multirow{2}{*}{$\begin{array}{c}\text { Mustard } \\
\text { yield } \\
\left(\mathbf{k g}^{\prime} \cdot \mathbf{h a}^{-1}\right)\end{array}$} & \multirow{2}{*}{$\begin{array}{c}\text { Spinach }^{\text {X }} \\
\text { yield } \\
\left(\mathbf{k g} \cdot \mathrm{ha}^{-1}\right)\end{array}$} \\
\hline & $\begin{array}{c}\text { Yield } \\
\left(\mathbf{k g} \cdot \mathrm{ha}^{-1}\right)\end{array}$ & $\begin{array}{c}\text { Head wt } \\
(\mathrm{g})\end{array}$ & $\begin{array}{c}\text { Yield } \\
\left(\mathrm{kg} \cdot \mathrm{ha}^{-1}\right)\end{array}$ & $\begin{array}{l}\text { Head wt } \\
(\mathrm{g})\end{array}$ & & \\
\hline One row $/ 1-m$ bed & $9,887 b^{x}$ & $171 \mathrm{a}$ & $42,838 \mathrm{~b}$ & 1287 & $24,187 \mathrm{c}$ & $5,380 \mathrm{c}$ \\
\hline Two rows $/ 1-\mathrm{m}$ bed & 13,402 a & $137 \mathrm{~b}$ & $40,046 \mathrm{~b}$ & $848 b$ & $33,704 \mathrm{~b}$ & $11,881 \mathrm{~b}$ \\
\hline Four rows $/ 2-\mathrm{m}$ bed & ...w & -.. & $43,662 b$ & $943 \mathrm{~b}$ & $34,558 \mathrm{~b}$ & $9,971 \mathrm{~b}$ \\
\hline Six rows $/ 2-\mathrm{m}$ bed & 13,292 a & $142 \mathrm{~b}$ & 51,844 a & $867 \mathrm{~b}$ & 40,711 a & $14,815 \mathrm{a}$ \\
\hline cV & 52.3 & 30.7 & 23.1 & 15.0 & 14.8 & 14.8 \\
\hline
\end{tabular}

m beds yielded $40 \%$ more than mustard planted in a single row on 1-m beds. Seeding rates for the six-row plots were six times greater than seeding rates for the single-row plots. One plant line/row was used in the onerow configuration, while two plant lines/row were used in the other configurations. A 20\% higher yield was recorded for mustard in the six-row configuration as compared with mustard in the two- or four-row configurations.

Spinach grown in six rows on 2-m beds produced $64 \%, 20 \%$, and $33 \%$ more yield than spinach on single-, two-, or four-row plots, respectively. Seeding rate for the six-row configuration of spinach was nine times the rate used to plant the single-row plots. Yield from spinach planted in singlerow/bed was 55\% less than the yield from two-row plots and $46 \%$ less than the yield from four-row plots. Differences among yields produced on twoand four-row plots were not significant.

\section{Conclusions}

Increasing the plant density by expanding the number of rows per bed increased the yields of cabbage and mustard. Highest production was obtained when these two crops were grown on the six-row configuration. Head size of cabbage was highest on the single-row configuration, but was adequate for fresh-market cabbage grown on all multiple-row configurations.

Observations based on one season of testing indicated that the yield of spinach and broccoli may be increased by planting in multiple rows. Highest production was recorded for spinach grown on the six-row configuration and broccoli grown on twoor six-row configurations. As with cabbage, head weight was highest for broccoli grown on single row/bed, but was adequate to meet size standards of the fresh market on multiple row configurations.

Weed control was excellent in all planting configurations. Planting density did not affect the timing of the initial cultivation as plant growth at this time was not sufficient to shade or crowd the weed species. Visual observations were made of all plantings at subsequent cultivations. Due to the broader plant cover at the high plant densities, plantings in the four- and 
six-row configurations appeared to be cleaner than the one- or two-row configurations. However, when the number of weeds were counted in multiplerow plantings with the same crops in other work by Parish et al. (1990), no differences in weed numbers were recorded among the different row configurations.

Cultivation of multiple narrow rows is difficult and unwieldy with conventional equipment, but with the system tested in these experiments subsequent cultivations were performed efficiently and effectively. Damage to the crops due to mechanical cultivation was minimal, although some injury did occur on cabbage grown on multiple-row configurations when the heads on the outside rows grew into the path of the cone-guide wheels. Cultivation within $8 \mathrm{~cm}$ of the plant row was accomplished easily in all the crops grown with the use of the cone-guide wheels on the precisely shaped and planted beds.

Careful attention should be paid to fertility practices when planting broccoli and cabbage on multiple rows/bed. To maintain acceptable head size, the plants must be fertilized sufficiently to compensate for the high plant populations. Although head size is not a factor with leafy vegetables, yields of mustard and spinach also may be reduced if fertilizer rates are not adequate. Additional research is necessary to determine optimum fertilizer rates necessary for producing these crops on multiple-row configurations.

Planting in multiple rows/bed did not affect the incidence or amount of diseases or insects. Good spray equipment with appropriate spray nozzles, proper pressure, and calibration is essential in any commercial vegetable operation. Most commercial units can be used for spraying multiple rows/ bed with no changes in sprayer configuration.

The precision cultural system used in these experiments was determined to be acceptable for growing broccoli, cabbage, mustard, and spinach in multiple rows/bed. Growing these crops in multiple rows/bed offers potential yield increases, but would be difficult and impractical with conventional equipment. The cultural system described here facilitates planting, cultivation, and fertilization using mechanically guided implements on precisely shaped beds. With the exception of the bed shaper, the equipment was assembled from commercially available components, which were easily acquired from equipment dealers and assembled in a research shop. No special or unusual tools or machines were used to build the equipment. The bed shaper was designed and constructed by the Dept. of Agricultural Engineering. Plans for the bed shaper are available from the Louisiana Cooperative Extension Service (Chaney and Parish, 1987), and construction of the implement can be accomplished in a local shop.

\section{Literature Cited}

Arthur, T. 1988. Breaking into vegetables. Amer. Veg. Grower 36(8):10-11.

Cannon, J.M. and J.E. Boudreaux, 1987. Commercial vegetable production recommendations. Louisiana Coop. Ext. Serv., Baton Rouge.

Chancy, P.P. and R.L. Parish. 1987. Engineering plans for building a bed shaper. Louisiana Coop. Ext. Serv., Baton Rouge.

Denison, J.E. and K.W. Paxton. 1987. Estimating the potential for vegetable pro- duction on cotton farms. Louisiana Agr. 31(2):3, 12, 17.

Dufault, R.J. and L. Waters, Jr. 1985. Interaction of nitrogen fertility and plant populations on transplanted broccoli and cauliflower yields. HortScience 20(1):127128.

Klassen, P. 1988. Cotton operation diversifies to vegetables. Amer. Veg. Grower 36(1):10, 12.

Mulkey, W.A. and W.C. Porter. 1987. Maximizing cabbage yields and packout in northeast Louisiana. Louisiana Agr. 31(1):16-17.

Parish, R.L., R.P. Bracy, D.W. Wells, and P.E. Bergeron. 1990. A comparison of cultivation methods for commercial vegetable crops. Amer. Soc. Agr. Eng. Paper 90-1041.

Parish, R.L., W.A. Mulkey, W.A. Meadows, P.P. Chaney, T.P. Talbot, and P. Hildalgo. 1988. Direct seeding of cole crops in Louisiana. Louisiana Agr. 31(4): 4-5.

Parish, R.L. and D.E. Mermoud. 1974. Evaluating wide-bed narrow-row culture in soybeans, grain sorghum, and corn. Arkansas Farm Res. 23(2):6.

Parish, R.L., S.M. Brister, and D.E. Mermoud. 1973. Preliminary results of widebed narrow-row cotton research. Amer. Soc. Agr. Eng. Paper 73-1578.

Sims, W.L. 1985. Cultural modification of vegetables for mechanized production. HortScience 20(6): 1005-1008.

\section{Acknowledgements}

This work was supported by a research grant from the Italian Trade Commission. The support of Asgrow Seed Company and Ferry-Morris Seed Company in providing seed for these tests is gratefully acknowledged. 